Document downloaded from:

http://hdl.handle.net/10251/146187

This paper must be cited as:

Torregrosa, AJ.; Broatch, A.; Margot, X.; Gómez-Soriano, J. (09-1). Understanding the unsteady pressure field inside combustion chambers of compression-ignited engines using a computational fluid dynamics approach. International Journal of Engine Research. 1-13. https://doi.org/10.1177/1468087418803030

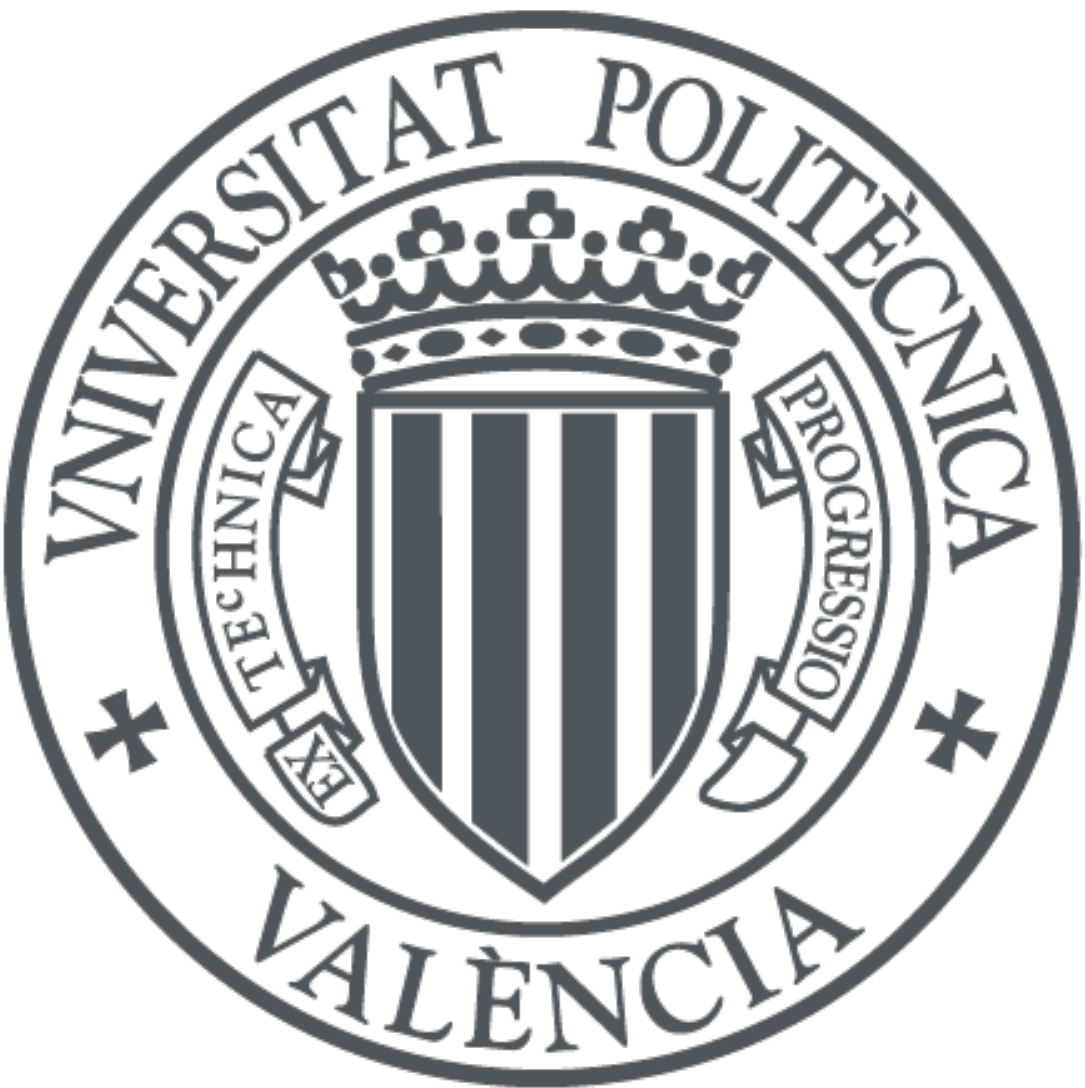

The final publication is available at

https://doi.org/10.1177/1468087418803030

Copyright SAGE Publications

Additional Information 


\title{
Understanding the unsteady pressure field inside combustion chambers of compression-ignited engines using a CFD approach
}

\author{
Antonio J. Torregrosa, Alberto Broatch, Xandra Margot and Josep Gomez-Soriano
}

\begin{abstract}
In this paper a numerical methodology for assessing combustion noise in compression ignition engines is described with the specific purpose of analysing the unsteady pressure field inside the combustion chamber. The numerical results show consistent agreement with experimental measurements in both the time and frequency domains. Nonetheless, an exhaustive analysis of the calculation convergence is needed to guarantee an independent solution. These results contribute to the understanding of in-cylinder unsteady processes, especially of those related to combustion chamber resonances, and their effects on the radiated noise levels. The method was applied to different combustion system configurations by modifying the spray angle of the injector, evidencing that controlling the ignition location through this design parameter it is possible to decrease the combustion noise by minimizing the resonance contribution. Important efficiency losses were, however, observed due to the injector/bowl matching worsening which compromises the performance and emissions levels.
\end{abstract}

\section{Keywords}

Combustion noise, CFD modelling, Frequency analysis, Cl engine, Resonance

\section{Introduction}

The automotive sector is a highly competitive market in which any technological advance can imply a significant benefit with respect to direct competitors. Engine manufacturers are constantly trying to achieve higher efficiency levels, while reducing exhaust emissions to accomplish with pollutant regulations. Currently, compression ignition (CI) Diesel engines for automotive applications have become really complex and expensive due to their high requirements in terms of performance and sustainability ${ }^{1}$. Such requirements have led to the design of downsized engines with aggressive turbocharging strategies and expensive exhaust after-treatment systems, thus making engine design and development a multidisciplinary and complex process. Different optimization techniques have been used in early design stages 2,3 , when improving the combustion system design ${ }^{4,5}$ or even during engine calibration in order to meet the required demands.

Since performance and ecological requirements have been substantially covered, engine noise has often been overlooked and excluded from the optimization procedures, mainly due to its complexity and lack of awareness. The seriousness of noise disorders, such as permanent hearing loss and even hypertension, have promoted several studies aiming at determining a safe threshold for the noise level ${ }^{6}$. As a consequence, governments have promoted the control of noise emissions. In addition, the sound quality of the engine noise perceived by the customers plays an important role in their purchasing decision, increasing the concern of the engine manufacturers about noise-related issues.

The ignition of a fluid volume containing a reactive mixture acts as an acoustic source by inducing pressure instabilities. This source can be generated both as a consequence of the combustion process itself and due to unsteady heat release. Depending on the application, the relative importance of the contribution of these two causes may be extremely different, and thus a proper understanding of the unsteady features of combustion is essential for studying the interaction between the combustion process and its corresponding acoustic effects. For instance, combustion noise in aero-engines is mainly produced by heat release fluctuations due to the instabilities caused by flame dynamics $^{7,8}$. However, in positive displacement devices, such as internal combustion engines (ICE), the interplay between thermal and acoustical phenomena is completely different due to their cyclic, unsteady operation, and to the fact that the process occurs in a closed fluid domain ${ }^{9,10}$.

In CI engines operating with conventional Diesel combustion (CDC), two different phases can be distinguished in the combustion process. During the first phase, the charge is self-ignited and burned in premixed conditions at different locations inside the combustion chamber. The burning rate is primarily controlled by chemical kinetics, causing an abrupt energy release. In the second phase, a diffusion flame is established and the energy may be assumed to be released at the same rate as the fuel mixes with air. The rate of heat

CMT - Motores Térmicos, Universitat Politècnica de València, Camino de Vera s/n, 46022 Valencia, Spain

\section{Corresponding author:}

Alberto Broatch, CMT - Motores Térmicos, Universitat Politècnica de València, Camino de Vera s/n, 46022 Valencia, Spain

Email: abroatch@mot.upv.es 
release (RoHR) is smoother than in the previous phase, and local heat fluctuations appear as a consequence of the diffusion flame dynamics. Both combustion phases contribute to the existence of an unsteady flow field, but the pressure instabilities generated during the premixed combustion phase are significantly larger, and they dominate the acoustic source by far.

The pressure instabilities are propagated as pressure waves, whose different interactions and reflections at the chamber walls force the gas to oscillate according to particular patterns. This phenomenon, that may be observed by the presence of high frequency oscillations along the in-cylinder pressure evolution, is traditionally referred to as combustion chamber resonance ${ }^{11}$. As a result, the pressure spectrum, especially in the high frequency range, depends on the relative position of local sources inside the chamber ${ }^{12,13}$. The natural frequency of these oscillation patterns, or resonant modes, depends on the gas temperature and the combustion chamber geometry. Therefore, all axial (longitudinal) modes are out of the human hearing range owing to the characteristic length of the combustion chambers used in automotive applications. In addition, the transversal (radial and azimuthal) modes of third order or higher are out of the human hearing range ${ }^{14}$ whereas the transversal modes of first or second order correspond to characteristic frequencies within the highly sensitive human perception span. The amplitude of these pressure oscillations is related to the pressure gradients achieved and to the relative position of the self-ignition areas in the combustion chamber $^{15}$.

Therefore, while single pressure transducer measurements provide enough information for analyzing thermodynamic conditions during the combustion process, the recreation of the in-cylinder unsteady pressure field demands additional measurement points across the combustion chamber ${ }^{16}$. Researchers have resorted to apply numerical methods for reproducing this field instead of building complex and expensive engine modifications for assessing the problem experimentally ${ }^{17}$. In line with this approach, computational fluid dynamics (CFD) codes are tool most commonly used to recreate the pressure field conditions in automotive applications ${ }^{18,19}$. However, the turbulent transport simulation remains as the main limiting aspect for the achievement of accurate results.

Direct Numerical Simulation (DNS) produces very accurate results by solving the turbulence transport equation directly, but its prohibitive computational cost makes it unsuitable for ICE applications, and its use is limited to small domains with very specific purposes. Large Eddy Simulation (LES) techniques decompose the flow field into large and small scales. The large scales are solved exactly whereas the small ones are approached by several models ${ }^{20,21}$. Anisotropic effects, such as intermittency due to misfires or large scale fluctuations, may be reproduced, proving the suitability of LES methods for simulating the unsteady heat release in established flames ${ }^{22}$ or even cycle-to-cycle pressure variations in spark ignition (SI) engines $^{23-25}$. These techniques are still very demanding in terms of computational requirements for ICE applications. Unsteady Reynolds Averaged Navier-Stokes (U-RANS) is the standard approach in most practical ICE flows. The low
Table 1. Engine and injector specifications

\begin{tabular}{ll}
\hline Engine type & Direct-injection Diesel engine \\
\hline Number of cylinders [-] & 4 in line \\
Displacement $\left[\mathrm{cm}^{3}\right]$ & 1600 \\
Bore - Stroke $[\mathrm{mm}]$ & $75-88.3$ \\
Connecting rod length [mm] & 137.1 \\
Compression ratio [-] & $18: 1$ \\
Number of valves [-] & 2 intake and 2 exhaust \\
Injector nozzles & 6 \\
Nozzle holes diameter $[\mu \mathrm{m}]$ & 124 \\
Included spray angle [deg] & 150 \\
\hline
\end{tabular}

computation time demanded has promoted its wide usage in the automotive industry. These methods assume that velocity variations around the mean value are small and only due to turbulence ${ }^{26}$, allowing to address cyclic variations associated only with isotropic turbulence.

Broatch et al. ${ }^{27}$ evidenced the suitability of CFD with URANS approaches to reproduce the spectrum of in-cylinder pressure in a 2-stroke CI engine. They also evidenced the influence of the local thermodynamic conditions at the start of combustion on the combustion process and, consequently, on the subsequent noise generation. Additionally, they proposed the use of the noise sources resulting from CFD calculations as a basis for noise propagation methods such as Anderton's standard attenuation curve ${ }^{28}$ or others ${ }^{29,30}$.

In this paper, a numerical methodology is presented with the objective of reproducing the unsteady pressure field inside the combustion chamber in CI Diesel engines. The final target is to contribute to the understanding of in-cylinder phenomena by evaluating possible strategies for controlling combustion noise by reducing the resonance contribution.

The paper is organized as follows: first, the experimental facility is briefly described and the numerical tools are presented. Then, the numerical methodology is detailed and the results obtained are displayed and validated. Finally, some conclusions about the methodology and its results are summarized, and further steps in the investigation are suggested for expanding its applicability.

\section{Experimental configuration}

The experimental characterization was carried out in the same light-duty high-speed direct-ignition (HSDI) Diesel engine used in previous investigations ${ }^{29}$. The engine is representative of the current design trends, with a downsized four-cylinder configuration, and equipped with a common rail injection system and a turbocharger. A 6-nozzle injector with hole diameters of $124 \mu \mathrm{m}$ and an included spray angle of $150^{\circ}$ was used in all the tests. The piston design provides a geometric compression ratio of 18 . The main specifications of the engine and the injector are summarized in Tab. 1.

The engine was directly coupled to an asynchronous electric brake for proper engine speed control. The brake was physically and acoustically isolated with sound damping panels so as to prevent eventual interferences in the measurement of engine noise. The test bench was installed inside an anechoic chamber that ensures free-field conditions for frequencies above $100 \mathrm{~Hz}$.

In-cylinder pressure was measured with a Kristler 6055Bsp piezoelectric transducer placed between the intake 
valves at the glow plug location. The noise radiated by the engine block was measured using a free-field microphone ${ }^{29}$ and a Head Acoustics HMS III system ${ }^{30}$. The pressure and noise signals were sampled using a dedicated acquisition system and recorded during 50 consecutive engine cycles. All signals were also registered with a sample frequency of $50 \mathrm{kHz}$, thus ensuring an aliasing-free bandwidth similar to the human hearing range, according to the Nyquist criterion $^{31}$. The rate of heat release and other relevant combustion parameters were calculated from the in-cylinder pressure trace by means of the energy equation and some reasonable assumptions ${ }^{32,33}$.

\section{Combustion noise diagnostics}

The characterization of the combustion noise is based on the in-cylinder pressure decomposition proposed by Payri et al. ${ }^{34}$. In this method, in-cylinder pressure is decomposed into three frequency intervals, each linked to one of the three contributions to the engine cycle: compressionexpansion, combustion phase and resonance phenomenon. This procedure also allows to identify which parameters are those most influential in each frequency band. Subsequent investigations ${ }^{29,30}$ have found cause-effect relations between the source and both the objective and subjective effects of noise. According to Torregrosa et al. ${ }^{29}$ the engine radiated noise or overall noise $(\mathrm{ON})$ can be obtained by means of

$$
\mathrm{ON}=C_{0}+C_{n} I_{n}+C_{1} I_{1}+C_{2} I_{2}
$$

where $C_{i}$ are empirical coefficients dependent on the engine size and concept.

The operation indicator, $I_{n}$, depends on both the engine speed $(n)$ and the idle engine speed $\left(n_{\text {idle }}\right)$ as

$$
I_{n}=\log \left[\frac{n}{n_{\text {idle }}}\right]
$$

The first combustion indicator $\left(I_{1}\right)$ that characterizes the sudden rise of pressure during the combustion event, is defined as

$$
I_{1}=\frac{n}{n_{\text {idle }}}\left[\frac{(\mathrm{d} p / \mathrm{d} t)_{\mathrm{comb}_{1}}^{\max _{1}}+(\mathrm{d} p / \mathrm{d} t)_{\mathrm{comb}}^{\max _{2}}}{(\mathrm{~d} p / \mathrm{d} t)_{\mathrm{comp}}^{\max }}\right]
$$

where $(\mathrm{d} p / \mathrm{d} t)_{\text {comb }}^{\max _{1}}$ and $(\mathrm{d} p / \mathrm{d} t)_{\text {comb }}^{\max _{2}}$ are the two maximum values of the pressure time-derivative during combustion, and $(\mathrm{d} p / \mathrm{d} t)_{\text {comp }}^{\max }$ is the highest peak of the pressure timederivative during the compression-expansion phase.

The second combustion indicator $\left(I_{2}\right)$ is related to the resonance phenomena inside the combustion chamber and it is mathematically expressed as

$$
I_{2}=\log \left[E_{0} \frac{E_{\text {res }}}{E_{\text {comp }}}\right]
$$

Here $E_{0}$ is a convenient scaling factor and $E_{\text {res }}$ is the signal energy of the resonance pressure oscillations. This parameter characterizes the global amplitude of the pressure oscillations due to the resonance phenomenon and its definition, as usual in the field of signal processing, is

$$
E_{\mathrm{res}}=\int_{\mathrm{IVC}}^{\mathrm{EVO}} p(t)_{\mathrm{res}}^{2} \mathrm{~d} t
$$

Table 2. RNG turbulence model constants.

\begin{tabular}{ccccccc}
\hline$C_{\mu}$ & $1 / \operatorname{Pr}_{k}$ & $1 / \operatorname{Pr}_{t}$ & $c_{\epsilon_{1}}$ & $c_{\epsilon_{2}}$ & $c_{\epsilon_{3}}$ & $\beta$ \\
\hline 0.0845 & 1.39 & 1.39 & 1.42 & 1.68 & -1.0 & 0.0012 \\
\hline
\end{tabular}

where $p(t)_{\text {res }}$ is the resonance pressure signal, which is integrated between intake valve closing (IVC) and exhaust valve closing (EVO). Other similar metrics are available in the literature. For instance, the peak pressure rise rate (PPRR) or the ringing intensity (RI). However, Shahlari et al. ${ }^{35}$ have evidenced their weakness for characterizing the resonance phenomenon when the combustion strategy, engine platform or operating conditions change. In fact, $E_{\text {res }}$ appears to offer the best reliability for the quantification of the amplitude of the pressure oscillations because it is based on the pressure trace and not on indirect parameters ${ }^{36}$.

Payri et al. ${ }^{30}$ verified that the same two combustion indicators also correlate with the perceived sound quality of the combustion noise. The sound quality is quantified by a mark ranging from 0 to 10 which represents the customer satisfaction degree, and can be expressed as

$$
\text { MARK }=10-C_{3} I_{1}-C_{4} I_{2}
$$

where coefficients $C_{i}$ are also dependent on the engine size and concept.

Moreover, in order to evaluate the source of combustion noise at each operation condition, the overall pressure level, termed 'cylinder pressure level' (CPL), is estimated by

$$
\mathrm{CPL}(\mathrm{dB})=10 \log \frac{P_{N}^{2}}{p_{0}^{2}}
$$

where $p_{0}=20 \mu \mathrm{Pa}$ and

$$
P_{N}=\frac{1}{N} \sum_{f=f_{1}}^{f_{N}} P(f)
$$

where $N$ is the number of harmonics between $f_{1}$ and $f_{N}$, while $P(f)$ represents the Fast Fourier Transform of the pressure signal $(p(t))$.

\section{Numerical model set-up}

The commercial CFD code CONVERGE was chosen for reproducing the dynamics of the in-cylinder flow through the mass, momentum and energy conservation equations. The finite volume method was selected for the numerical solution of the governing equations with a second-order accurate spatial scheme. Additional equations were also considered in order to calculate the transport of species. The turbulent flow properties were approximated by using the Unsteady Reynolds-averaged Navier-Stokes (URANS) renormalization group (RNG) model $^{37}$ with estimated wall heat fluxes ${ }^{38}$ and the recommended constants values shown in Tab. 2. The Redlich-Kwong equation ${ }^{39}$ was selected as the equation of state required for calculating the compressible flow properties. The pressure-velocity coupling was achieved by using a modified Pressure Implicit with Splitting of Operators (PISO) method ${ }^{40}$.

The fuel injection event was modelled by the standard Discrete Droplet Model (DDM) ${ }^{41}$ while the spray properties 


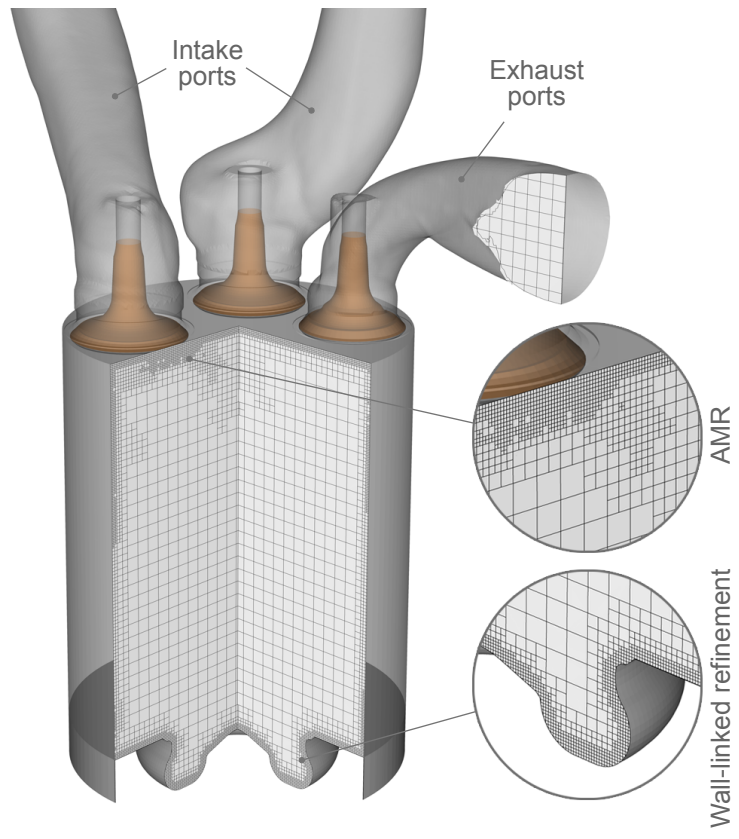

Figure 1. Computational domain and mesh properties of the engine architecture at IVC.

such as liquid atomization and drop breakup were simulated by means of the Kelvin-Helmholtz Rayleigh-Taylor (KHRT) model $^{42}$. The physical properties of the fuel were predicted by choosing the n-heptane as a surrogate. Concerning combustion, the code approaches the detailed chemical kinetics through a direct integration of the surrogate fuel chemical mechanism by means of the SAGE (detailed transient chemistry solver) solver ${ }^{43-45}$. The chemical mechanism was based on a Primary Reference Fuel (PRF) blend of $n$-heptane and iso-octane, deactivating the iso-octane reactions so as to predict the diesel ignition features. An adapted reaction mechanism with 42 species and 168 reactions was derived from the ERC-Multichem mechanism ${ }^{46}$ for representing the diesel fuel chemistry through the PRF oxidation.

The three-dimensional domain, displayed in Fig. 1, included the complete single cylinder geometry and the intake-exhaust ports, allowing to perform fully coupled gas exchange process (GEP) and combustion simulations. The whole domain was discretized in a structured mesh of hexahedrons with a base cell size of $3 \mathrm{~mm}$. The original mesh size was reduced in areas where the complexity of the physical and chemical phenomena increases. Three levels of grid refinement were added to the walls of the combustion chamber and the ports, in the spray zones and in the whole combustion chamber during the combustion process. These adjustments were done to improve the thermal boundary layer prediction, the reflection and the interaction of the pressure waves and the precision in the modelling of chemical reactions and spray properties (atomization, breakup, coalescence, etc.). In addition, the code used an adaptive mesh refinement algorithm (AMR) to increase the spatial resolution where both velocity and temperature gradients are significant. The total number of cells depended on the simulation timing and varied between $1.5 \times 10^{6}$ cells at Bottom Dead Centre (BDC) and $0.5 \times 10^{6}$ at Top Dead Centre (TDC). This mesh configuration was achieved after

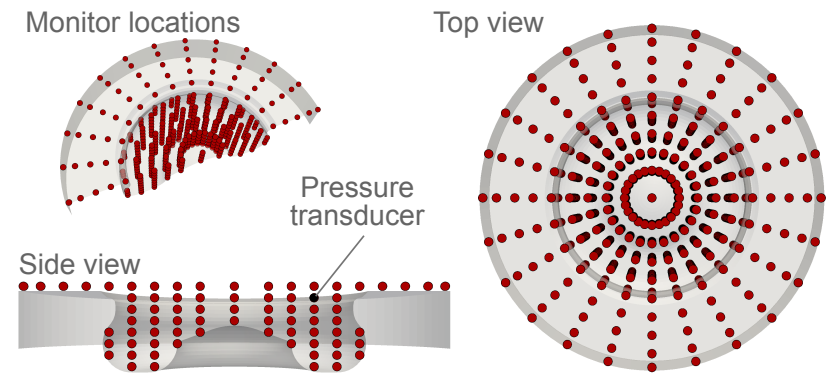

Figure 2. Registration points (monitors) allocated along the combustion chamber.

a grid independence study ${ }^{47}$, offering a mesh-independent solution for the pertinent acoustic parameters described in the previous section.

Isothermal conditions were imposed at the solid walls of the cylinder liner, piston and head surfaces, and intake and exhaust ports and valves. Wall temperatures were estimated by means of a lumped heat transfer model ${ }^{48}$. The inflow/outflow boundaries placed at the end of the intake and exhaust ports were established from the mean value of instantaneous pressure and temperature measurements. The species concentrations at these boundaries were considered uniform and they were estimated with simplified models. The initial conditions of the flow (pressure, temperature, velocity field and species concentration) were determined by means of OD approaches and direct measurements.

A monitor point was placed exactly at the same location as the pressure transducer in order to compare the simulated and the experimental pressure signals for validation. Additionally, 844 monitor points were distributed across the combustion chamber (see Fig. 2) in order to analyse the location of the standing waves. The pressure and all the other variables computed were recorded at a sampling frequency of $50 \mathrm{kHz}$ so as to provide an aliasingfree bandwidth sufficient to cover the human hearing range.

The simulations were performed between two consecutive exhaust valve openings, encompassing a complete engine cycle. The time step was optimized following a dynamic strategy based on two different Courant number definitions:

$$
\begin{gathered}
C_{u}=u \frac{\Delta t}{\Delta x} \\
C_{c}=c \frac{\Delta t}{\Delta x}
\end{gathered}
$$

where $u$ is the flow velocity, $c$ is the speed of sound, $\Delta x$ is the cell size and $\Delta t$ is the time step. The time step was determined by considering a Courant number close to one, the minimum cell size in the domain and the significant characteristic velocity: the flow velocity during the GEP and the compression, and the speed of sound in the combustion phase in order to ensure an accurate prediction of pressure wave propagation. The return time for a full-single cycle simulation, 720 crank angle degrees (cad), was about 130 hours when the calculation was distributed on 32 parallel threads. The cluster used to perform all the calculations consists of 4 Fujitsu RX500 servers and 72 Fujitsu BX920 blades with 1280 parallel threads. 


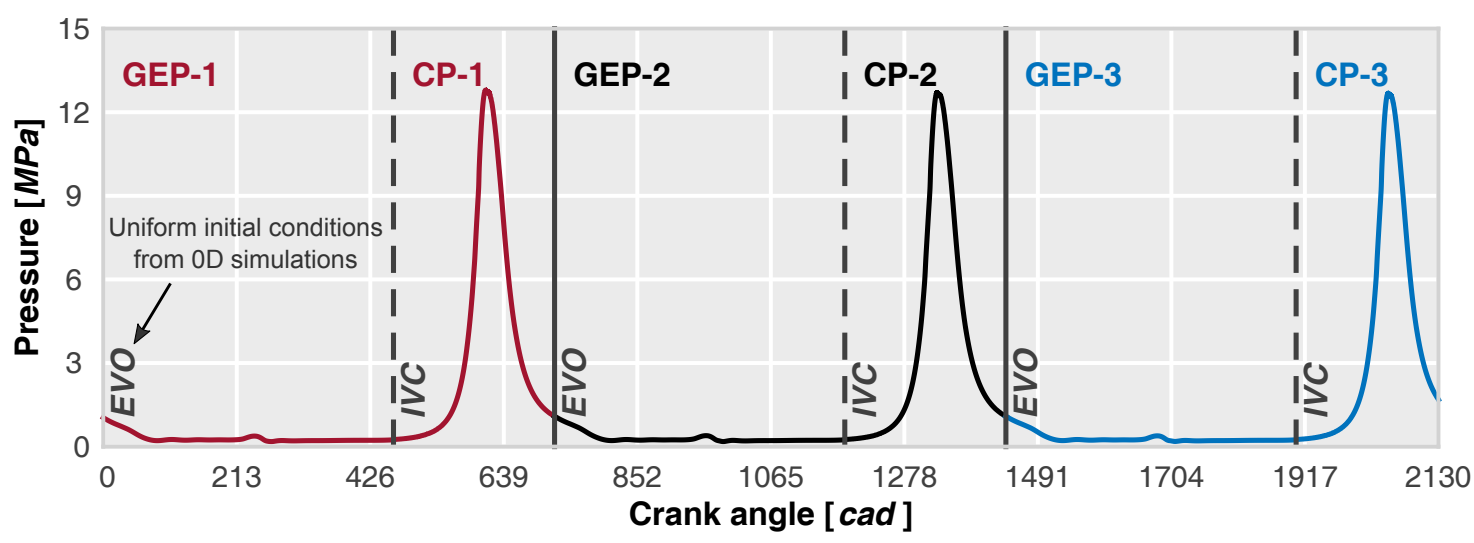

Figure 3. A schematic representation of the CFD methodology and the initial conditions definition. In-cylinder pressure evolution of three consecutive engine cycles.

\section{Methodology}

\section{Description}

Traditionally, the engine spectrum is divided in three regions of interest ${ }^{49}$. The low frequency range, commonly ranged between 0 and $400 \mathrm{~Hz}$, is exclusively caused by the compression-expansion process itself without any contribution of combustion. Within the rest of the spectrum, there are two different regions in which the pressure waves behaviour can be consider distinct. In the middle range of frequencies, approximately gathered between $400 \mathrm{~Hz}$ and 4 $\mathrm{kHz}$, the pressure waves generated by combustion are within the plane wave regime since there are no spatial gradients. Lastly, the high frequency range, with frequencies higher than $4 \mathrm{kHz}$, is characterized by the standing wave behaviour caused by the resonant gas oscillations ${ }^{11}$.

Several numerical methods for analysing Diesel combustion are available in the literature. Some works ${ }^{50,51}$ focused on combustion diagnosis, performance and emissions, assume simplifications so as to reduce the mesh size and the simulation time. Some of those assumptions are mainly related to the definition of the boundary and the initial conditions. In particular, periodic suppositions and a uniform distribution of the thermodynamic variables for initialization were applied by considering angular sectors and simple thermodynamic models which can compromise the in-cylinder unsteady pressure field prediction. Periodic boundary conditions cannot reproduce the pressure wave interaction and reflection mechanisms correctly, thus affecting negatively to the high frequency band of the pressure spectrum. In addition, local thermodynamic conditions, turbulence and species concentration determine the fuel ignition features (spatial and temporal sequence) which is the main cause of the unsteady pressure behaviour within the combustion chamber $^{47}$.

With all these aspects in mind, a novel methodology was defined with the basis of the CFD model described in the previous section. It consisted on simulating the entire engine cycle including both the GEP and the combustion phase with a calculation domain formed by the complete cylinder and the intake and exhaust ports. The GEP started at EVO with uniform initial conditions at the whole domain in terms of pressure, temperature, turbulence and species concentration, and the velocity field was fixed as null at the start of the

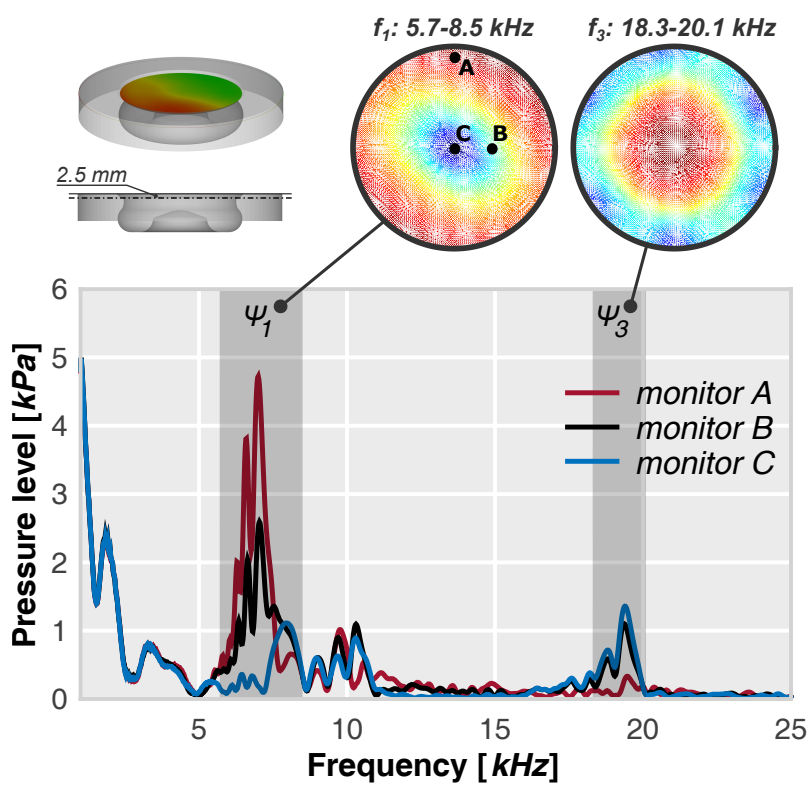

Figure 4. An example of the interpolation method for visualizing the resonant modes. The method is applied to the reference case for displaying both first $\left(\psi_{1}\right)$ and third $\left(\psi_{3}\right)$ transversal modes.

simulation. Once the GEP is calculated, the combustion phase (CP) starts with the resulting flow conditions at IVC (intake valve closing). In addition, the methodology includes the possibility of simulating several consecutive cycles (multi-cycle) for improving its capability to predict the unsteady pressure field inside the cylinder. In those subsequent cycles, the initial conditions were determined as a result of the previous cycle. Figure 3 illustrate the proposed methodology by the in-cylinder pressure evolution along the three consecutive cycles.

As mentioned above, traditional in-cylinder pressure measurements through a single transducer do not provide enough information for evaluating the effects of the resonance. The presented methodology compares the simulated and the measured pressure profiles at the same location of the pressure transducer, checking the consistency between the numerical results and the measurements. After this check, the solution is considered suitable for extrapolation to the entire domain. With the additional information supplied by the numerical model it is possible 
to link the temporal variation of the pressure with a specific position. This relation was established by using multiple monitors allocated in the combustion chamber (see Fig. 2).

This method offers flexibility to relate the effects observed in the frequency domain with the position where they occur. In Fig. 4 an application of this procedure is presented. The sound pressure level (SPL) associated with the first $\left(\psi_{1}\right)$ and third $\left(\psi_{3}\right)$ transversal modes was obtained for each monitor through Fast Fourier Transform (FFT) and filtering techniques (band-pass filter). These values were interpolated between all monitor locations allowing to plot the SPL associated with a specific frequency band in contour plots at a given plane. In particular, in the example displayed in Fig. 4, $5.7-8.5 \mathrm{kHz}$ and $18.3-20.1 \mathrm{kHz}$ band-pass filters were applied to visualize $\psi_{1}$ and $\psi_{3}$ transversal modes in a plane perpendicular to the cylinder axis and located $2.5 \mathrm{~mm}$ away from the cylinder head.

\section{Discussion}

Using this methodology, the global thermodynamic conditions and the heat release rate shown in Fig. 5 were obtained. Here, the signals were separated in cycles and superposed for comparison. Figure 5a displays the in-cylinder pressure of each simulated cycle during the GEP process. There are not significant gaps between all the cycles. However, the thermodynamic conditions predicted by the CFD model at EVO after the first cycle are not exactly the same as those predicted by the OD model for initializing the simulation. This causes slight differences between the first and the subsequent cycles during the opening phase of the exhaust valves. In spite of this disagreement, the prediction of the in-cylinder pressure at IVC is not significantly affected.

Figure $5 \mathrm{~b}$ shows that the mean temperature estimation exhibit a significant dispersion. The second and third cycles follow similar trends, while the first cycle exhibits a higher deviation from the other ones. In addition, the estimation of the mean temperature at IVC presents a significant deviation between the first and the subsequent cycles $\left(\simeq 15^{\circ} \mathrm{K}\right)$, influencing the charge mass available for combustion. Figure $5 \mathrm{~d}$ shows the effects on the heat release of the mentioned disagreement. The ignition delay in the combustion of the first pilot injection is decreased in the second and third cycles and the maximum value of the RoHR is increased due to the higher mean temperatures and the lower mass trapped inside the cylinder. The maximum RoHR produced by the second ignition is larger in the first cycle than in the subsequent ones. During the main injection the differences are scarce and only the maximum RoHR presents a slight disagreement during the mixing controlled combustion. The differences observed are not only related with the global thermodynamic conditions, but with the local conditions which could also play a relevant role in the prediction of the combustion properties and its effects. Figure 6 shows a series of snapshots of temperature contours just before the first ignition timing of each simulated engine cycle. There are considerable gradients of temperature inside the combustion chamber, showing a hotspot located on the side of the exhaust valves. The simulation of the first cycle allows to reproduce the in-cylinder temperature gradients but it does not achieve the same value of those predicted by the following simulated cycles.
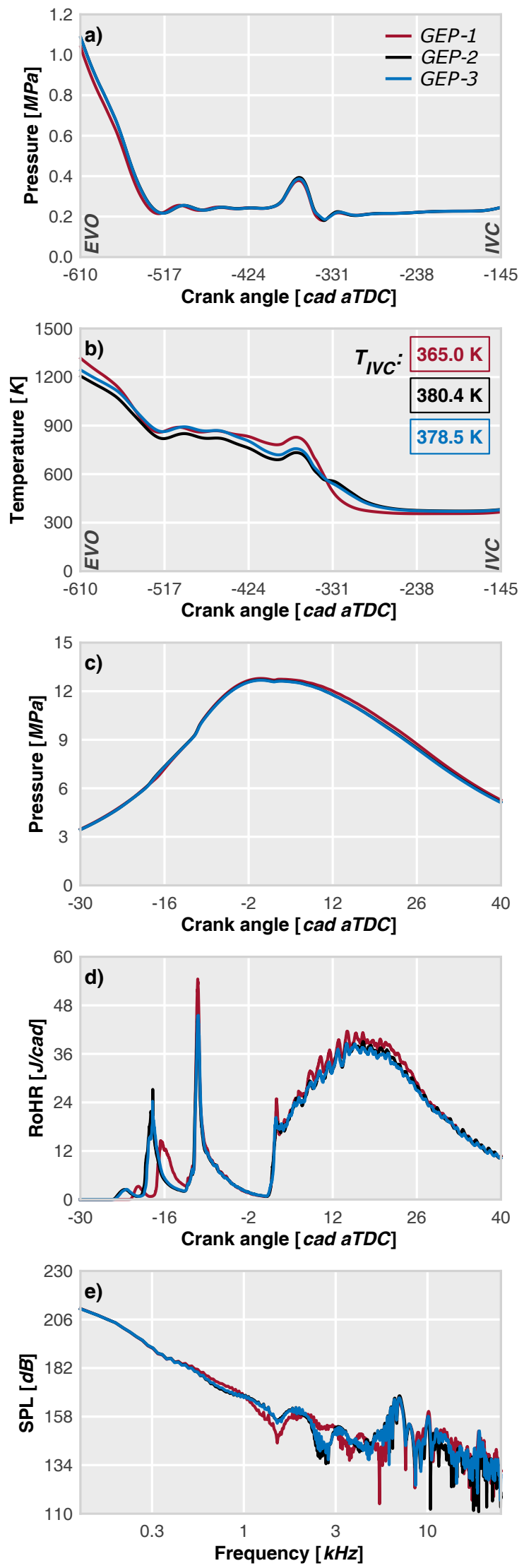

Figure 5. Analysis of the solution dispersion between three consecutive engine cycle calculations. a) In-cylinder mean pressure during the GEP, b) In-cylinder mean temperature during the GEP, c) In-cylinder mean pressure during the combustion phase, d) RoHR during the CP, e) In-cylinder pressure spectrum at the transducer location. (Units cad aTDC mean crank angle degrees after Top Dead Center) 


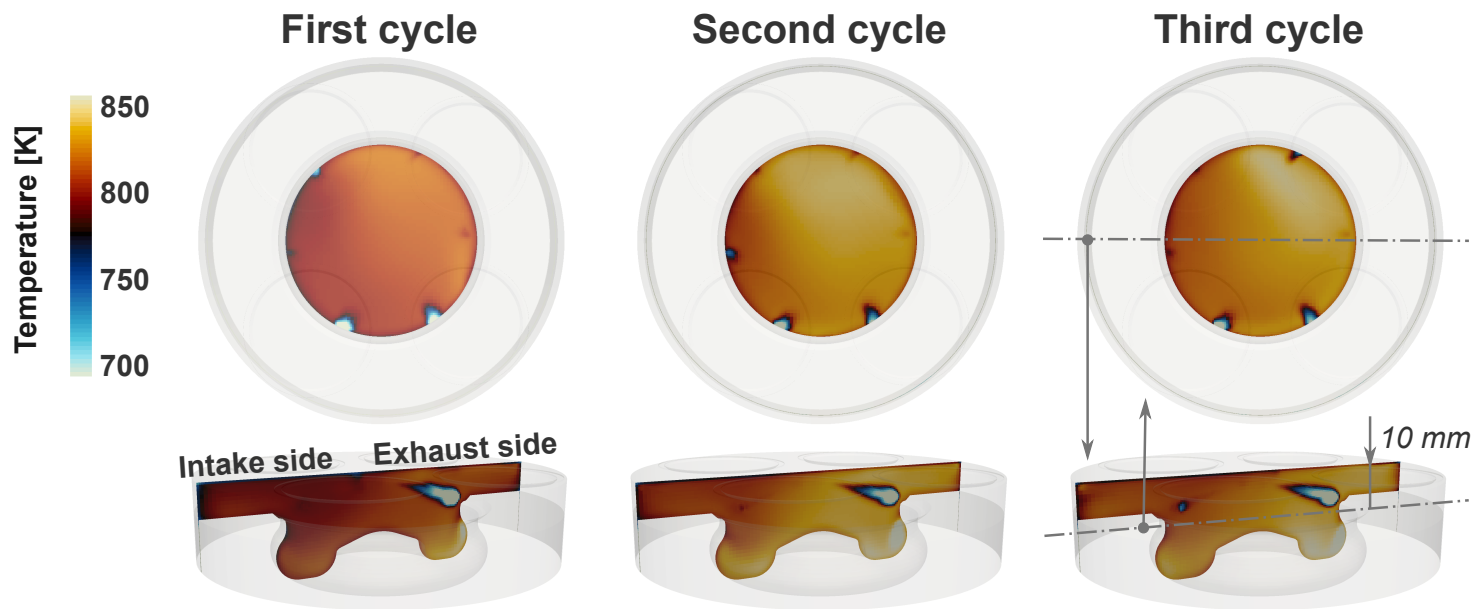

Figure 6. Changes in the local temperature distribution at the start of combustion ( $\simeq-25$ cad after TDC). Snapshots of temperature contours at two different planes.

Table 3. Comparison of the estimated metrics related to internal and external fields

\begin{tabular}{lllll}
\hline Parameters & Experiment & Cycle 1 & Cycle 2 & Cycle 3 \\
\hline$(\mathrm{d} p / \mathrm{d} t)_{\max _{1}}[\mathrm{MPa} / \mathrm{cad}]$ & 0.555 & 0.922 & 0.815 & 0.824 \\
$(\mathrm{~d} p / \mathrm{d} t)_{\max _{2}}[\mathrm{MPa} / \mathrm{cad}]$ & 0.504 & 0.453 & 0.548 & 0.514 \\
$E_{\mathrm{res}}\left[\mathrm{kPa}{ }^{2} \mathrm{~s}\right]$ & 27.66 & 29.93 & 30.55 & 27.60 \\
$\mathrm{CPL}[\mathrm{dB}]$ & 223.98 & 230.63 & 230.48 & 230.47 \\
ON [dB] & 90.0 & 91.14 & 91.12 & 90.96 \\
MARK [-] & 5.89 & 4.99 & 5.02 & 5.12 \\
\hline
\end{tabular}

The in-cylinder mean pressure evolution does not change significantly between the three cycles during the combustion phase (see Fig. 5c). However, there are noticeable differences in the estimation of $(\mathrm{d} p / \mathrm{d} t)_{\max _{1}}$ and $(\mathrm{d} p / \mathrm{d} t)_{\max _{2}}$, as it is observed in Tab. 3. Their close relation with the maximum heat release values achieved during the combustion of the two pilot injections explains the higher deviation of the first cycle. In addition, Fig. 5e shows that the dispersion in those parameters gives rise to relevant differences in the middle frequency band of the pressure spectra ${ }^{27}$. In contrast, the resonance energy shows similar values between all cycles and the high frequency pressure spectra do not display remarkable differences.

Table 3 also presents an estimation of the three external-field parameters detailed in the "Combustion Noise Diagnosis" section. They were obtained with the measured reference cycle and also with the CFD model predictions. Despite the differences observed in the pressure spectra, neither ON nor MARK metrics are significantly affected, and no relevant dispersion is observed between the radiated engine noise parameters. Examination of the $I_{1}$ definition, can clarify why these parameters are not significantly affected in spite of the noticeable differences found in the pressure time-derivative. During the first cycle, the overestimation of $(\mathrm{d} p / \mathrm{d} t)_{\max _{1}}$ is compensated by the underestimation of $(\mathrm{d} p / \mathrm{d} t)_{\max _{2}}$, producing an $I_{1}$ estimation similar to those obtained in the second and third cycles. Therefore, in this case a single cycle calculation does not ensure an accurate solution of the in-cylinder unsteady processes, and further cycles must be simulated for improving the reliability of the results.

Hence, the solution convergence was established after the simulation of two consecutive cycles, when the dispersion in the main thermodynamic parameters, such as pressure and temperature, was significantly reduced and the prediction of the pressure spectrum did not change significantly in consecutive cycles.

\section{Validation}

A steady operation condition defined by a medium speed (2400 rpm) and a medium load (168 Nm) was selected to validate the numerical methodology. At this operating point, the injection and intake pressures are 80 and 0.206 $\mathrm{MPa}$, respectively. The validation method was based on comparing the in-cylinder pressure profile obtained by direct measurements and CFD calculations in both the time and the frequency domains. In the CFD simulations, the instantaneous in-cylinder pressure was registered with a monitor placed at the same location as the transducer. In Fig. 7a comparison of the pressure profiles is presented together with that of the rate of heat release. The relative error in the pressure trace does not exceed $6.15 \%$, and thus the agreement between the estimation and the measurements may be regarded as good. The RoHR traces present some differences, specially during the mixing-controlled combustion phase, where the calculation underestimates the heat release rate. Nevertheless, the model reproduces the tendency of energy release and can therefore be considered sufficiently accurate to reproduce the combustion process.

In Fig. $7 b$ the pressure spectra are compared with the reference cycle and the measurement dispersion. The CFD estimation coincides with the measurements in almost the whole frequency range, with only a slight disagreement being observed for frequencies around 700$800 \mathrm{~Hz}$. Additionally, Tab. 3 shows that both ON and MARK predictions present deviations similar to the measurement 

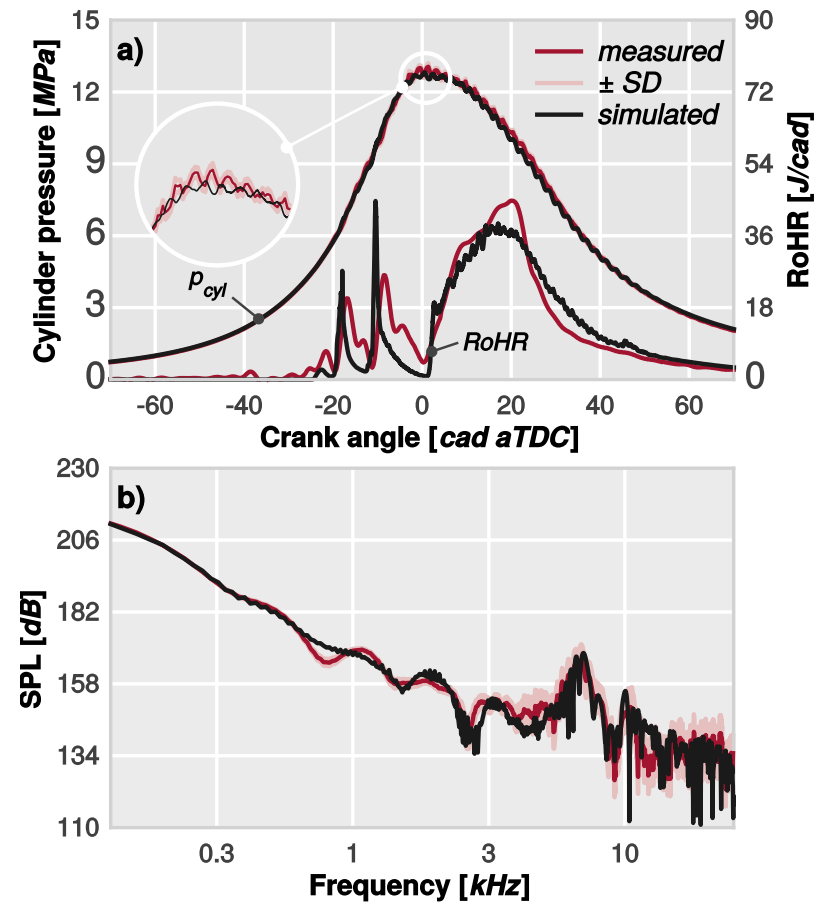

Figure 7. Comparison between measurement and CFD calculation. The standard deviation (SD) is included in order to compare the solution with the measurement dispersion due to cycle-to-cycle variations. a) In-cylinder pressure and RoHR traces, b) Pressure spectra traces.

uncertainty $(\approx 1 \mathrm{~dB})$ and the mark quotation $(\approx 0.5)$, respectively, thus ensuring an accurate prediction of both metrics related to the external acoustic field.

\section{Example of application}

Several authors $12,13,52$ have demonstrated theoretically that the relative position of the combustion excitation can determine the standing wave behaviour inside ICE combustion chambers, modifying the amplitude of the resonant modes. The excitation of a specific resonant mode can be avoided by producing the flow disturbance at the same location of its node or zero amplitude region. Conversely, the same level of excitation enhances the contribution of a particular resonant mode as the application point is located away from the node.

In this section, the proposed methodology was applied to three different combustion system configurations in order to evaluate the contribution of the ignition location to the resonance phenomenon. The combustion system was redesigned by decreasing the injector included spray angle, and the engine operating conditions were maintained as those used on the validation. Therefore, since the injection pressure was kept constant ( $80 \mathrm{MPa}$ ) in all simulated cases, the included angle was changed by modifying the injector geometry, this is, by adjusting only the inclination of the nozzles. The main idea of this study was to displace the ignition points towards the centre of the cylinder, while the excitation was kept constant so as to reduce the amplitude of the most relevant mode $\left(\psi_{1}\right)$.

Figure 8a show the maximum pressure time-derivative reached during each combustion stage (first pilot, second pilot and main injection). The results indicate the consistency of $(\mathrm{d} p / \mathrm{d} t)_{\max }$ for these three hardware configurations, demonstrating that the excitations were kept constant and ensuring that the impact on the resonance was only due to the change in the ignition position, not to the intensity of the excitation.

Trends in the energy of the resonance are presented in Figs. $8 \mathrm{~b}$ and $8 \mathrm{c}$. First, a comparison of the $E_{\text {res }}$ obtained at the transducer location is shown in Fig. 8b. As expected, this parameter decreases with the included spray angle since, as it was intended, the ignition locations were moved towards the node of the first transversal mode. Secondly, an averaged value of $E_{\text {res }}$ for all monitors was obtained in order to verify that the global resonance energy inside the combustion chamber follows the same trend and that the first transversal mode $\left(\psi_{1}\right)$ is clearly the most important one. Figs. 8d and 8e display the impact on the objective (ON) and subjective (MARK) aspects of noise. A significant lowering of the overall noise was achieved $(\approx 0.6 \mathrm{~dB})$ whereas the sound quality was also improved $(\approx 0.3)$. However, these improvements in terms of the unsteady response come together with important efficiency losses due to the worsening in spray/bowl matching, as can be seen in Fig. $8 \mathrm{f}$.

The ignition areas can be identified by locating the places in which the fuel energy release is produced. Hence, taking advantage of the CFD results, the RoHR was numerically integrated along the whole domain with respect to the radial coordinate so as to analyse both the temporal and the spatial evolution of the combustion process. The solutions are presented in Fig. 9 in which the horizontal axis indicates the temporal evolution of the engine cycle, the vertical axis shows the integration variable -the normalized radial position $R^{\text {norm }}$ - and the colour scale
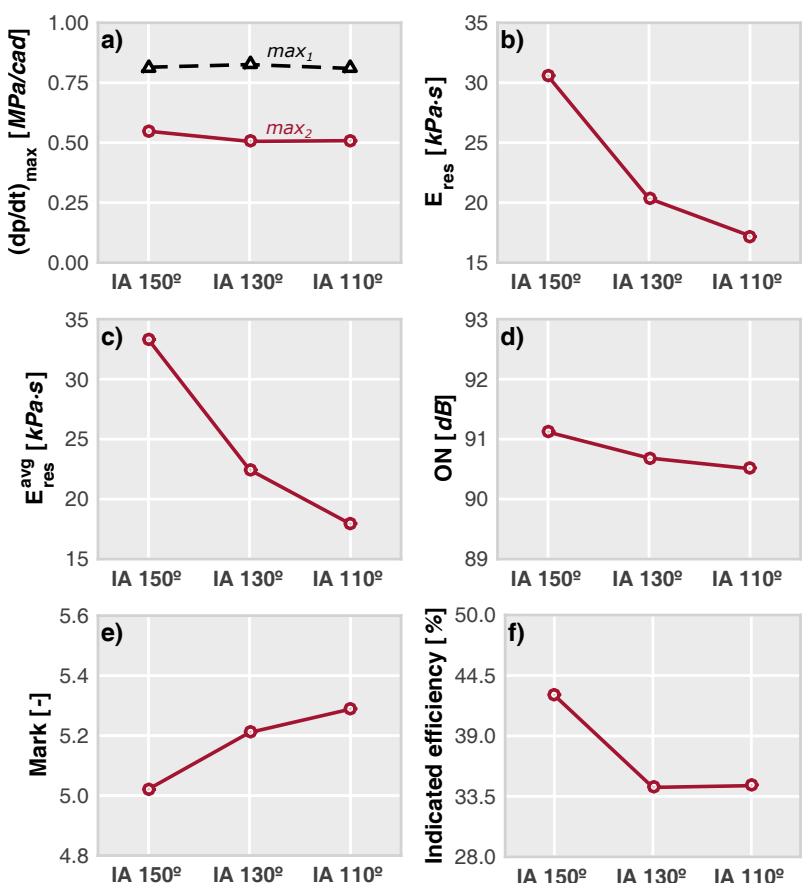

Figure 8. Effects of the included spray angle variation. a) Maximum pressure time-derivative due to each combustion phase, b) Energy of resonance at the transducer location, c) Averaged energy of resonance, d) Overall noise (ON), e) sound quality quotation (MARK), f) Indicated efficiency. 

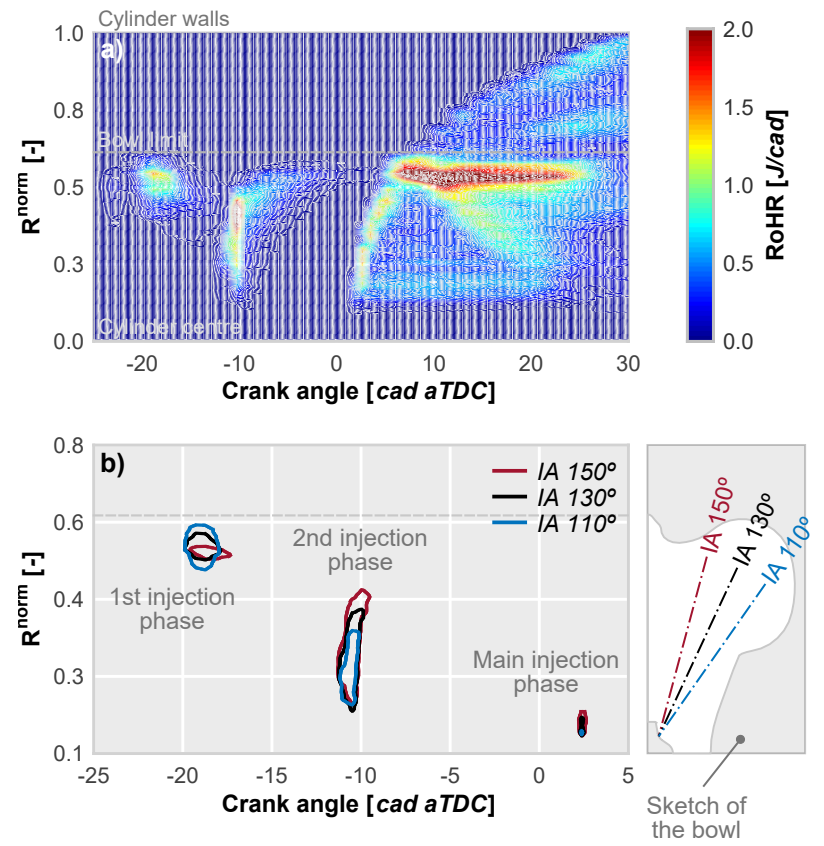

Figure 9. Ignition areas identification. a) RoHR contours along the radial dimension of the engine cylinder for the reference case, b) Comparison of the ignition variation.

displays the energy release. The ignition locations were established by identifying the 99 percentile of the RoHR distribution values. This value guarantees that the energy release is sufficiently meaningful for its consideration as an ignition area. In addition, the RoHR associated with mixingcontrolled combustion was neglected in view of its low contribution to the resonance phenomenon.

The energy distribution for the reference case (IA $150^{\circ}$ ) is displayed as an example in Fig. 9a. This method was applied to the three engine configurations and the position of the ignitions was presented in Fig. 9b. As it can be seen, the combustion of the first pilot injection is essentially located at the same radial position in all the cases. Poor density conditions cause a high ignition delay and a deep spray penetration, forcing the combustion to start close to the bowl limit even for the closest included spray angles. In the same way, the burning of the main injection does not present relevant differences in terms of radial location. However, in this case, fuel ignites very close to the injector nozzle due to the extreme thermodynamic conditions achieved close to TDC. By contrast, significant differences appear in the ignition location of the second injection. It is evident that the self-ignition event is moved towards the cylinder centreline as the included spray angle is reduced. The second combustion is therefore dominant in the resonance phenomenon due both to its highest intensity $(\mathrm{d} p / \mathrm{d} t)_{\max }$ and to its ignition location.

In order to analyse the frequency distribution of incylinder pressure for each hardware configuration, the pressure spectrum averaged across all the monitors in the domain is plotted in Fig. 10. The mid-frequency range does not exhibit significant differences between all the cases considered, thus confirming its relation with the $(\mathrm{d} p / \mathrm{d} t)_{\max }$ due to the combustion event. The high frequency content varies with the engine configuration: the amplitude of the first mode is decreased and higher order modes are excited as the spray angle is reduced.

The spatial distribution of the resonant modes can be examined by using the monitor interpolation procedure described previously. In particular, three different bandpass filters were applied to the pressure registered by all the monitors in order to inspect the most relevant modes for each hardware configuration (filter cut-off frequencies are shown in Fig. 10). In the same Fig. 10 the spatial pressure distributions are displayed by plotting the SPL across a plane perpendicular to the cylinder axis. The SPL was normalized between the minimum and maximum values of each mode for proper scaling and visualization. It can be observed that the spatial distribution of the nonsymmetric ${ }^{1}$ modes $\left(\psi_{1}\right.$ and $\left.\psi_{2}\right)$ varies when the ignition location is moved whereas their characteristic frequencies do not change significantly. However, the highest order mode $\left(\psi_{3}\right)$, which has a symmetric distribution, does not exhibit any meaningful differences in its characteristic frequency and spatial distribution.

\section{Conclusions}

In this paper, a numerical methodology for assessing combustion noise in CI Diesel engines has been presented, with the target of understanding the unsteady pressure field

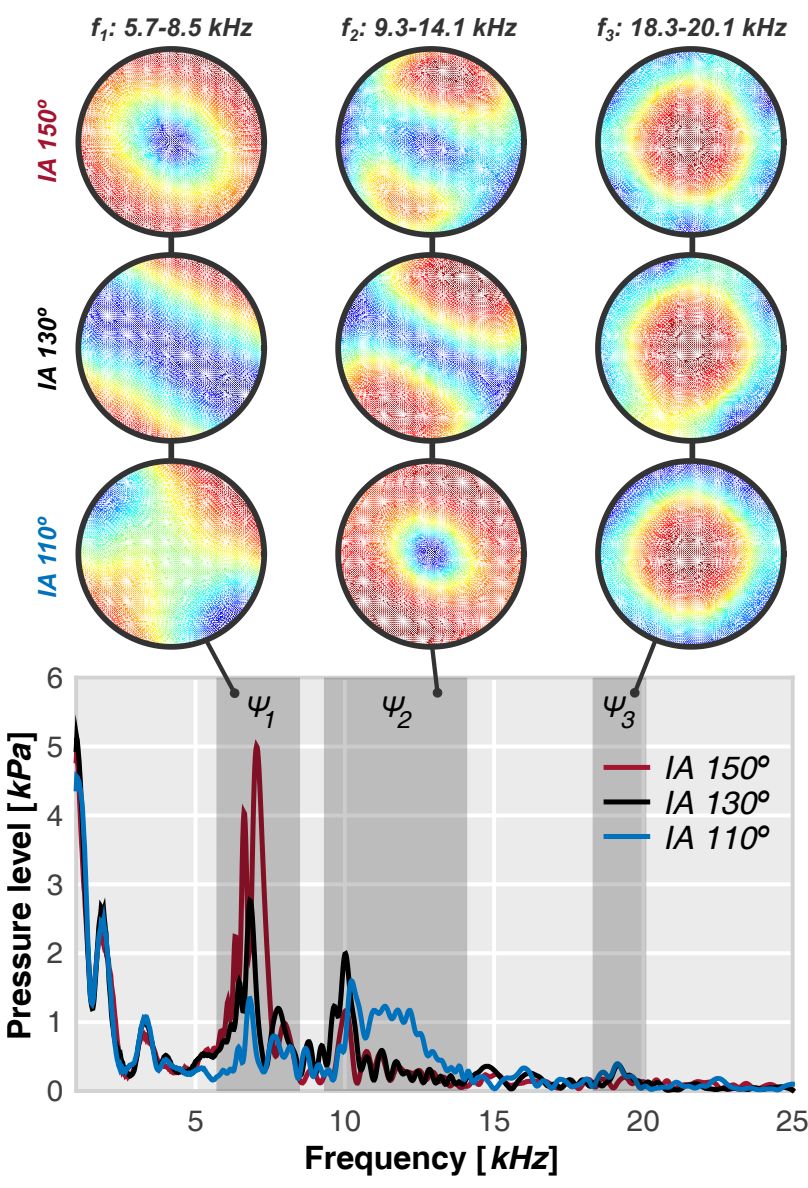

Figure 10. A comparison of the pressure spectrum averaged across all considered monitors for the three combustion system configurations. Spatial pressure distribution of the most relevant modes of resonance are plotted at a perpendicular slide to the cylinder axis located at $2.5 \mathrm{~mm}$ of the cylinder head. 
inside the combustion chamber and identifying the relevant combustion issues. In particular, special attention has been put on minimizing the contribution of the high frequency pressure oscillations in order to promote quieter combustion systems.

During this research, the main limiting factor was ensuring an accurate solution of the in-cylinder pressure field, especially in the frequency domain. Therefore, a detailed procedure has been devised so as to determine a coherent convergence criterion which assures a representative solution. In the case considered, it is necessary to simulate multiple engine cycles to reach the calculation convergence, and to guarantee an accurate prediction of the in-cylinder pressure in both domains.

The overall amplitude of the high frequency pressure spectra can be reduced by modifying the fuel ignition location through the injector nozzle design. A reduction in the included spray angle forces the fuel to ignite close to the cylinder centre, close to the node of the first mode. This strategy reduces the amplitude of the first mode, exciting higher order modes and increasing their pressure level. In spite of the increase in amplitude observed in these other modes, their pressure level never become comparable to that of the first mode due to the higher characteristic frequency, and therefore, due to the larger energy demanded.

By applying the described visualization methods based on a combination of both interpolating and filtering techniques, the spatial distribution of the resonant modes has been examined. Results allow the identification of spatial changes in the pressure distribution when the ignition position is modified. For non-symmetric modes, the excitation point determines the shape of the modes, giving rise to different oscillation patterns while their natural frequencies are kept constant. Modes with symmetric distributions, however, do not vary neither in shape nor in frequency when the excitation location is moved.

Despite the attractive benefits of reducing combustion noise by means of a simple modification in the injector design, the worsening attained in spray/bowl matching produces a drastic decrease in the indicated efficiency, and it also compromises the pollutant emissions levels.

In summary, the methodology presented has permitted to identify the keys for reducing the combustion noise by acting on the acoustic source, and to determine possible drawbacks which might compromise its potential application.

Further analysis is nonetheless needed for a better understanding of the unsteady pressure field by applying advanced analysis techniques, such as Proper Orthogonal Decomposition (POD) or Dynamic Mode Decomposition (DMD), in order to identify all the relevant phenomena. In addition, further efforts should be undertaken for considering multiple combustion system design parameters as inputs for the optimization of combustion noise together with the traditional engine performance and emissions parameters.

\section{Acknowledgements}

The authors want to express their gratitude to CONVERGENT SCIENCE Inc. and Convergent Science GmbH for their kind support for performing the CFD calculations using CONVERGE software.

\section{Declaration of conflicting interests}

The authors declare no potential conflicts of interest.

\section{Funding}

The equipment used in this work has been partially supported by FEDER project funds "Dotación de infraestructuras científico técnicas para el Centro Integral de Mejora Energética y Medioambiental de Sistemas de Transporte (CiMeT)" [grant number FEDER-ICTS-2012-06], framed in the operational program of unique scientific and technical infrastructure of the Spanish Government. J. Gomez-Soriano is partially supported through the Programa de Apoyo para la Investigación y Desarrollo (PAID) of Universitat Politècnica de València [grant number FPI-S2-20161353].

\section{Notes}

1. The axisymmetric nodes are traditionally designated as symmetric modes while all other modes are denoted as nonsymmetric $^{11,14}$.

\section{References}

1. Benajes J, Novella R, De Lima D et al. Analysis of combustion concepts in a newly designed two-stroke high-speed direct injection compression ignition engine. International Journal of Engine Research 2015; DOI:10.1177/1468087414562867.

2. Costa M, Bianchi GM, Forte C et al. A Numerical Methodology for the Multi-objective Optimization of the DI Diesel Engine Combustion. Energy Procedia 2014; 45: 711720. DOI:10.1016/j.egypro.2014.01.076.

3. Hiroyasu H, Miao H, Hiroyasu T et al. Genetic Algorithms Optimization of Diesel Engine Emissions and Fuel Efficiency with Air Swirl, EGR, Injection Timing and Multiple Injections. SAE Technical Paper 2003; 2003-01-1853. DOI:10.4271/ 2003-01-1853.

4. Navid A, Khalilarya S and Taghavifar H. Comparing multiobjective non-evolutionary NLPQL and evolutionary genetic algorithm optimization of a DI diesel engine: DoE estimation and creating surrogate model. Energy Conversion and Management 2016; 126: 385-399. DOI:10.1016/j.enconman. 2016.08.014.

5. Benajes J, García A, Pastor JM et al. Effects of piston bowl geometry on Reactivity Controlled Compression Ignition heat transfer and combustion losses at different engine loads. Energy 2016; 98: 64-77. DOI:10.1016/j.energy.2016.01.014.

6. Masterton B, Heffner H and Ravizza R. The Evolution of Human Hearing. The Journal of the Acoustical Society of America 1969; 45(4): 966-985. DOI:10.1121/1.1911574.

7. Strahle WC. Combustion noise. Progress in Energy and Combustion Science 1978; 4(3): 157-176. DOI:10.1016/ 0360-1285(78)90002-3.

8. Flemming F, Sadiki A and Janicka J. Investigation of combustion noise using a LES/CAA hybrid approach. Proceedings of the Combustion Institute 2007; 31(2): 31893196. DOI:10.1016/j.proci.2006.07.060.

9. Klos D and Kokjohn SL. Investigation of the sources of combustion instability in low-temperature combustion engines using response surface models. International Journal of Engine Research 2015; 16(3): 419-440. DOI:10.1177/ 1468087414556135. 
10. Editorial. Cyclic dispersion in engine combustion-Introduction by the special issue editors. International Journal of Engine Research 2015; 16(3): 255-259. DOI:10.1177/ 1468087415572740.

11. Hickling R, Feldmaier DA and Sung SH. Knock-induced cavity resonances in open chamber Diesel engines. The Journal of the Acoustical Society of America 1979; 65(5): 1474-1479. DOI:10.1121/1.382910.

12. Torregrosa AJ, Broatch A, Margot $X$ et al. Combustion chamber resonances in direct injection automotive Diesel engines: a numerical approach. International Journal of Engine Research 2003; 5(1): 83-91. DOI:10.1243/ 146808704772914264.

13. Broatch A, Margot X, Gil A et al. Computational study of the sensitivity to ignition characteristics of the resonance in DI diesel engine combustion chambers. Engineering Computations 2007; 24(1): 77-96. DOI:10.1108/02644400710718583.

14. Eriksson LJ. Higher order mode effects in circular ducts and expansion chambers. The Journal of the Acoustical Society of America 1980; 68(2): 545-550. DOI:10.1121/1.384768.

15. Broatch A, Margot X, Novella R et al. Impact of the injector design on the combustion noise of gasoline partially premixed combustion in a 2-stroke engine. Applied Thermal Engineering 2017; 119: 530-540. DOI:10.1016/j.applthermaleng.2017.03. 081.

16. Vressner A, Lundin A, Christensen $M$ et al. Pressure Oscillations During Rapid HCCI Combustion. SAE Technical Paper 2003; 2003-01-3217. DOI:10.4271/2003-01-3217.

17. Tutak $\mathrm{W}$ and Jamrozik A. Validation and optimization of the thermal cycle for a diesel engine by computational fluid dynamics modeling. Applied Mathematical Modelling 2016; 40(13): 6293-6309. DOI:10.1016/j.apm.2016.02.021.

18. Payri F, Benajes J, Margot X et al. CFD modeling of the incylinder flow in direct-injection Diesel engines. Computers \& Fluids 2004; 33(8): 995-1021. DOI:10.1016/j.compfluid.2003. 09.003 .

19. Benajes J, Novella R, Lima DD et al. Impact of injection settings operating with the gasoline Partially Premixed Combustion concept in a 2-stroke HSDI compression ignition engine. Applied Energy 2017; 193: 515-530. DOI:10.1016/j. apenergy.2017.02.044.

20. Lesieur M, Métais O and Comte P. Large-Eddy Simulations of Turbulence. Cambridge University Press, 2005. DOI: 10.1017/CBO9780511755507.

21. Pope SB. Ten questions concerning the large-eddy simulation of turbulent flows. New Journal of Physics 2004; 6(1): 35. DOI: 10.1088/1367-2630/6/1/035.

22. Silva CF, Leyko M, Nicoud F et al. Assessment of combustion noise in a premixed swirled combustor via LargeEddy Simulation. Computers \& Fluids 2013; 78: 1-9. DOI: 10.1016/j.compfluid.2010.09.034.

23. Vermorel O, Richard S, Colin O et al. Multi-Cycle LES Simulations of Flow and Combustion in a PFI SI 4-Valve Production Engine. SAE Technical Paper 2007; 2007-01-0151. DOI:10.4271/2007-01-0151.

24. Jamrozik A, Tutak W, Kociszewski A et al. Numerical simulation of two-stage combustion in SI engine with prechamber. Applied Mathematical Modelling 2013; 37(5): 2961-2982. DOI:10.1016/j.apm.2012.07.040.

25. Qin W, Xie M, Jia $M$ et al. Large eddy simulation of incylinder turbulent flows in a DISI gasoline engine. Applied
Mathematical Modelling 2014; 38(24): 5967-5985. DOI: 10.1016/j.apm.2014.05.004.

26. Kaario O, Pokela $\mathrm{H}$, Kjäldman $\mathrm{L}$ et al. LES and RNG Turbulence Modeling in DI Diesel Engines. SAE Technical Paper 2003; 2003-01-1069. DOI:10.4271/2003-01-1069.

27. Broatch A, Margot X, Novella R et al. Combustion noise analysis of partially premixed combustion concept using gasoline fuel in a 2-stroke engine. Energy 2016; 107: 612-624. DOI:10.1016/j.energy.2016.04.045.

28. Anderton D. Relation between combustion system and engine noise. SAE Technical Paper 1979; 790270. DOI:10.4271/ 790270.

29. Torregrosa AJ, Broatch A, Martín J et al. Combustion noise level assessment in direct injection Diesel engines by means of in-cylinder pressure components. Measurement Science and Technology 2007; 18(7): 2131-2142. DOI:10.1088/ 0957-0233/18/7/045.

30. Payri F, Broatch A, Margot $X$ et al. Sound quality assessment of Diesel combustion noise using in-cylinder pressure components. Measurement Science and Technology 2009; 20(1): 01-12. DOI:10.1088/0957-0233/20/1/015107.

31. Ihlenburg F. The Medium-Frequency Range in Computational Acoustics: Practical and Numerical Aspects. Journal of Computational Acoustics 2003; 11(02): 175-193. DOI:10. 1142/S0218396X03001900.

32. Lapuerta M, Armas $\mathrm{O}$ and Hernández JJ. Diagnosis of DI Diesel combustion from in-cylinder pressure signal by estimation of mean thermodynamic properties of the gas. Applied Thermal Engineering 1999; 19(5): 513-529. DOI: 10.1016/S1359-4311(98)00075-1.

33. Payri F, Olmeda P, Martín J et al. A complete OD thermodynamic predictive model for direct injection diesel engines. Applied Energy 2011; 88(12): 4632-4641. DOI: 10.1016/j.apenergy.2011.06.005.

34. Payri F, Broatch A, Tormos B et al. New methodology for in-cylinder pressure analysis in direct injection diesel engines - application to combustion noise. Measurement Science and Technology 2005; 16(2): 540-547. DOI:10.1088/0957-0233/ 16/2/029.

35. Shahlari AJ, Hocking C, Kurtz E et al. Comparison of Compression Ignition Engine Noise Metrics in LowTemperature Combustion Regimes. SAE International Journal of Engines 2013; 6: 541-552. DOI:10.4271/2013-01-1659.

36. Wissink M, Wang Z, Splitter D et al. Investigation of Pressure Oscillation Modes and Audible Noise in RCCI, HCCI, and CDC. SAE Technical Paper 2013; 2013-01-1652. DOI: 10.4271/2013-01-1652.

37. Yakhot V and Orszag S. Renormalization group analysis of turbulence. Journal of Scientific Computing 1986; 1(1): 3-51. DOI:10.1007/BF01061452.

38. Angelberger $\mathrm{C}$, Poinsot $\mathrm{T}$ and Delhay B. Improving nearwall combustion and wall heat transfer modeling in SI engine computations. SAE Technical Paper 1997; 2003-01-0542. DOI:10.4271/972881.

39. Redlich $\mathrm{O}$ and Kwong JNS. On the Thermodynamics of Solutions. V. An Equation of State. Fugacities of Gaseous Solutions. Chemical Reviews 1949; 44(1): 233-244. DOI: 10.1021/cr60137a013.

40. Issa RI. Solution of the implicitly discretised fluid flow equations by operator-splitting. Journal of Computational Physics 1986; 62: 40-65. DOI:10.1016/0021-9991(86) 
90099-9.

41. Dukowicz JK. A particle-fluid numerical model for liquid sprays. Journal of Computational Physics 1980; 35(2): 229253. DOI:10.1016/0021-9991(80)90087-X.

42. Reitz RD and Beale JC. Modeling spray atomization with the Kelvin-Helmholtz/Rayleigh-Taylor hybrid model. Atomization and Sprays 1999; 9(6): 623-650. DOI:10.1615/AtomizSpr.v9. i6.40.

43. Senecal PK, Pomraning E, Richards KJ et al. MultiDimensional Modeling of Direct-Injection Diesel Spray Liquid Length and Flame Lift-off Length using CFD and Parallel Detailed Chemistry. SAE Technical Paper 2003; 2003-011043. DOI:10.4271/2003-01-1043.

44. Babajimopoulos A, Assanis DN, Flowers DL et al. A fully coupled computational fluid dynamics and multi-zone model with detailed chemical kinetics for the simulation of premixed charge compression ignition engines. International Journal of Engine Research 2005; 6(5): 497-512. DOI:10.1243/ 146808705X30503.

45. Pal P, Keum S and Im HG. Assessment of flamelet versus multi-zone combustion modeling approaches for stratifiedcharge compression ignition engines. International Journal of Engine Research 2016; 17(3): 280-290. DOI:10.1177/ 1468087415571006.

46. Brakora J and Reitz RD. A Comprehensive Combustion Model for Biodiesel-Fueled Engine Simulations. SAE Technical Paper 2013; 2013-01-1099. DOI:10.4271/2013-01-1099.

47. Torregrosa AJ, Broatch A, Gil A et al. Numerical approach for assessing combustion noise in compression ignition Diesel engines. Submitted to Applied Acoustics 2017;

48. Torregrosa AJ, Olmeda P, Degraeuwe B et al. A concise wall temperature model for DI Diesel engines. Applied Thermal Engineering 2006; 26(11-12). DOI:10.1016/j.applthermaleng. 2005.10.021.

49. Broatch A, López JJ, García-Tíscar J et al. Experimental analysis of cyclical dispersion in CI vs. SI engines and its significance for combustion noise numerical modelling. Submitted to Applied Thermal Engineering 2017;

50. Ciatti S, Johnson M, Adhikary BD et al. Efficiency and Emissions performance of Multizone Stratified Compression Ignition Using Different Octane Fuels. SAE Technical Paper 2013; DOI:10.4271/2013-01-0263.

51. Molina S, García A, Pastor JM et al. Operating range extension of RCCI combustion concept from low to full load in a heavyduty engine. Applied Energy 2015; 143: 211-227. DOI: 10.1016/j.apenergy.2015.01.035.

52. Broatch A, Margot X, Gil A et al. A CFD approach to diesel engine combustion chamber resonance. SAE Technical Paper 2007; 2007-24-0043. DOI:10.4271/2007-24-0043.

\section{Appendix}

\section{Acronyms}

AMR Adaptive Mesh Refinement

aTDC after Top Dead Centre

BDC Bottom Dead Centre

cad Crank Angle Degree

CDC Conventional Diesel Combustion

CFD Computational Fluid Dynamics

CI Compression-Ignited

CP Combustion Phase

CPL Cylinder Pressure Level

DDM Discrete Droplet Model

DMD Dynamic Mode Decomposition

DNS Direct Numerical Simulation

EVO Exhaust Valves Opening

FFT Fast Fourier Transform

GEP Gas Exchange Process

HSDI High Speed Direct Injection

IA Included Angle

ICE Internal Combustion Engine

IMEP Indicated Mean Effective Pressure

IVC Intake Valves Closing

KH Kelvin-Helmholtz

LES Large Eddy Simulation

ON Overall Noise

PISO Pressure Implicit with Splitting of Operators

POD Proper Orthogonal Decomposition

PPRR Peak Pressure Rise Rate

PRF Primary Reference Fuel

RANS Reynolds-averaged Navier-Stokes

RI Ringing Intensity

RNG Re-Normalized Group

RoHR Rate of Heat Release

RT Rayleigh-Taylor

SAGE Detailed Chemistry Solver

SD Standard Deviation

SI Spark-Ignited

SPL Sound Pressure Level

TDC Top Dead Centre

URANS Unsteady Reynolds-averaged Navier-Stokes 